\title{
Cultural Dimensions of Behaviors Towards E- Commerce in a Developing Country Context
}

\author{
Fahim Akhter \\ Department of Management Information Systems \\ College of Business Administration, \\ King Saud University, Riyadh, Saudi Arabia
}

\begin{abstract}
Customers prefer to shop online for various reasons such as saving time, better prices, convenience, selection, and availability of products and services. The accessibility and the ubiquitous nature of the Internet facilitate business beyond brick and mortar. The web-based businesses are required to understand the consumers' expectations, attitudes, and behavior across the globe and take into consideration of cultural effects. Saudi Arabia has become a highly potential lucrative market for web-based companies. However, the growing number of Saudi Internet users has not become leading online shoppers. It is important for web based companies to identify the barriers that are causing Saudi users to stay away from online shopping mainstream. This led to understanding Saudi culture, expectations, behavior, and decision-making process to promote e-commerce. The purpose of this study is to investigate the effects of Saudi Arabian culture on the diffusion process of e-commerce. The study addresses the cultural differences, risk perceptions, and attitude by investigating Saudi people about shopping online. An empirical study was conducted to collect the data from Saudi users.
\end{abstract}

Keywords-Electronic Commerce; Security; Culture; Online Shopping; Privacy; Saudi Arabia

\section{INTRODUCTION}

E-commerce is a globally accepted medium of conducting online business, and within a relatively short time, its services have risen to become a core element of the electronic business. The Census Bureau of the Department of Commerce declared that the estimate of U.S. retail e-commerce sales for the fourth quarter of 2015 was $\$ 89.1$ billion, an increase of 2.1 percent from the third quarter of 2015 [1]. E-commerce sales in the U.S. are projected to reach $\$ 482$ billion by 2018 [2], accounting for approximately $9 \%$ retail sales within the country. The number of digital buyers already reached 171 million in 2015 and continues to increase, with the total number of digital buyers projected to surpass 190 million by 2018. Credit and debit cards $(73 \%)$ are the payment method of choice for U.S. online shoppers with digital payments (16\%) increasing in popularity [2]. The growth of e-commerce is not in the U.S. alone, but the sign points towards continued growth globally.

There is now substantial evidence that the Internet has changed the way in which customers conduct online transactions in respect of their culture norms. This led us to assume that the success of the online business is subject to specific culture and norms. Due to it, web-based companies consider product localization to ensure business survival in the local market competition. The Chinese government and local online business do understand the importance of the benefits of e-commerce in terms of enhancing Chinese presence in the international business arena, strengthening business processes and channels, and forming better customer relationships [4]. Online trade in China skyrocketed by $120 \%$ [5] in the 2005 2015.

The researchers are agreed that a one of the main barriers facing the full deployment of e-commerce is the development of trust on the side of the consumer, particularly in developing countries [6]. The diverse characteristics of local environments and their cultures have created a significant level of variation in the acceptance of e-commerce. For example, a study [7] describes that Qatari people are vulnerable to e-mail phishing scheme. It has been found out that the country-specific factors, interests, beliefs, religion and personal characteristics are the main factor that causes Qatari citizens to become vulnerable to e-mail phishing attacks. The study has found that Qataris put too much trust in technology as compared to their own capabilities to detect email phishing.

Online vendors who target global customers could cultivate trustworthiness by acknowledging the norms and values of consumer culture. Nowadays, websites are accessed from any part of the world. Therefore, language, culture, and infrastructure issues top the list of online vendors [4]. It is beneficial for an online vendor to be accepted in a new culture being aware of the differences in language and customs that make up the culture in which they do business. It would be added value for vendors to understand the difficulties faced by customers to access their websites. Even though access to the Internet is very cheap in Europe and North America, some countries still charge heavy amounts for accessing the Internet. A report issued in 2001 by Human Rights Watch stated that many countries in the Middle East have been hesitant about allowing their citizens free access to the Internet. The report also notes that many countries in North Africa regularly monitor their citizen's access to the Internet and have taken steps to prevent the exchange of information outside their controls. In Pakistan and India, the respective governments use proxy servers to filter content. Some countries do not directly ban e-commerce, but do have strong local requirements that put extra pressure on vendors to compete in that segment. According to the report by U.S. Commercial Services on Buyusa.gov, the French government requires that an advertisement for products and services must be in French. Thus, a vendor who advertises and ships 
products to France may have to offer a French version of his website. Vendors could show their respect and values to local consumers by adopting a local culture's norms in their business. Vendors could adopt local norms by observing local dialogs and their meanings, and symbols, with respect to their products and services. As mentioned on English-Zone.com, Pepsi's "come alive" advertising campaign did not achieve much success in China because its message came across as "Pepsi brings your ancestors back from the graves." Therefore, it is important for vendors to adjust the content of the website if the language of the website's content is different from the language of those who will be using it.

Different cultures respond differently to design, images, vocabulary, and color schemes. For example, in India, it is inappropriate to use the image of a cow in a cartoon or in a laughable setting. Indian culture has a religious status for cow. Muslim countries can be offended by an image that shows human arms or legs uncovered. Some consumers may not like a web page's color scheme if it clashes with their norms. For example, a web page that has large white elements can be offensive to Japanese consumers because the color white is symbolic of death in their culture. It is also inappropriate for websites with English content in Japan to use the word "four" because in Japanese this is "shi," which is also associated with the word for death. In China, the word "clock" is similar to the word for "death" and white, blue or black are associated with funerals. Websites in China could use red, yellow and pink because they see as pleasurable colors. Websites can attract local customers by avoiding conflicting images, vocabulary or color scheme because cultural norms and values affect consumers' motives and attitudes towards choices, intentions, and behaviors [4]. A rigorous assessment of aspects of online transactions is suggested as further work in view of the scarcity of empirical research in this area. This paper reports, research carried out in Saudi Arabia, which investigated consumer's attitudes towards using computers and the Internet and their Internet usage patterns

This paper is divided into six sections. After this introduction, Section II includes a brief literature review. Section III introduces the methodology adopted in this research. Section IV discusses and concludes the research.

\section{LITERATURE REVIEW}

Researchers [16] have suggested that there are several barriers besides security and privacy, which contribute to the adoption of B2C e-commerce: consumer resources, age, knowledge, lifestyle, educational level, attitude, motivation, marital status, personality, values, and cultural values. These factors could have different weights in influencing a consumer's buying decision, depending on the local culture and lifestyle of the consumer. For example, the attitude of consumers towards online shopping in developed countries such as the UK or the U.S. may be different from consumers from less developed countries such as Pakistan, Bangladesh, United Arab Emirates and Saudi Arabia.

Many studies on the impact of cross-cultural [7] have revealed major differences among cultures in respect of shopping online. Therefore, there may be a strong relationship between online shopping and culture which requires further study. It has been reported [8] by Saudi managers that lack implementation of management information systems (MIS) is one of the barriers for not adopting-commerce. Many of the managers of the local companies have admitted that if they were using the MIS systems, they would be indulging in ecommerce

\section{METHODOLOGY}

Since the nature of the information needed in this research is related to opinions, attitudes, and beliefs, the online questionnaire was best suited for collecting data. Therefore, a qualitative research method in the form of a web-based survey was used to explore and understand how the Saudi consumers perceive and evaluate the risks of e-commerce. The survey included one open-ended question at the end, which allowed the respondents to comment in their own words. Respondents were asked to express their opinions with a number of statements on their online shopping experience.

The online survey targeted at students consisted of 12 questions about their attitudes towards online shopping, problems they are facing and how the experience of online shopping and services could be improved. There were 1,491 participants who received via e-mail an invitation to take part in the online survey. In this message, there was a link to the questionnaire. The final sample consisted of 141 males and 104 females. The data were collected between January 11 and February 28, 2016. About 73.21 percent of the subjects were between 18 and 27 years of age. The majority of the respondents $(61.23 \%)$ were studying at the undergraduate level and 98.12 percent had a computer and Internet access and were familiar with the online buying process. Web-based questionnaires were posted online along with a note that provided general information on the nature and the importance of the study and the significance of the contributions. Participants were assured of the confidentiality of their responses and promised a summary of the study results if they desired them. The data were collected through online surveys.

The instruments used in this research are adapted from the advice of fellow colleagues and experts in the research domain. The instruments used in this research were checked for validity, appropriateness, reliability, and accuracy. A number of steps were taken to meet this requirement. A panel of students, staff, and faculty at King Saud University were asked to answer the questionnaire and provide their comments on the wording and the content. Their feedback helped significantly in reforming the questionnaire. The analysis provided valuable suggestions such as shortening the questionnaire, changing some words, and using a common vocabulary. The researcher discussed the wording and the content of the questionnaire in detail with respondents.

\section{FINDINGS}

The collected data were analysed to extract Internet usage patterns. The composition of gender and its impact on Saudi Arabian society is rigorously analyzed. It is observed from the data that male respondents spend slightly more time $(58 \%)$ on the Internet as compared to female respondents (42\%). This means that men and women in almost equal numbers use the 
Internet, with a marginally higher percentage of men going online. It shows that 56 percent of male respondents spend more than 11 hours a day on surfing the Internet as compared to 44 percent of female users. The data also reveal that male respondents hold 62 percent of full-time employment as compared to 38 percent females. It has been noted that respondents who spend more time on the Internet also hold a higher percentage of full-time jobs as compared to those who spend less time on the Internet and hold less percentage of fulltime jobs

This study supports the interpretation that the gender that spends more time on the Internet in Saudi Arabia holds more full-time employment. This analysis indicates that users who spend more time on the Internet are likely to hold fulltime jobs as compared to those who spend less time on the Internet. The other interpretation of this analysis might be that more users access the Internet from workplaces as compared to from home.

Figure 1 shows that online shopping is positively related to the time spent on the Internet. It has been observed that respondents who spend more time surfing on the Internet also tend to buy products from online vendors. This analysis tends to point that users who spend more time on online surfing probably have a higher tendency to become potential customers.

The majority of the respondents access the Internet from work. It has been observed that 62 percent of respondents access the Internet from work while 38 percent access from another location, such as college, hotspot, and home

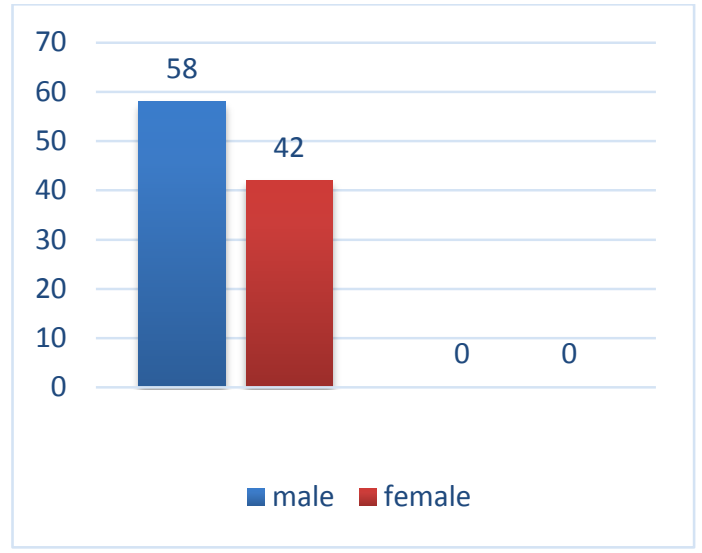

Fig. 1. Shopping Online

It is also noticed from the responses that users do not prefer to use Internet café facilities to access the Internet. This is a pretty interesting observation as Internet café is a popular option in other cultures such as in North America.

In has been observed that, Saudi Internet users are heavily using mobile devices to access social media platforms [Fig 2]. The most accessible social website, though mobile is Facebook $(65.56 \%)$ and Twitter $(33.73 \%)$. The statistics showed that users are inclined to explore online for entertainment, products, and services. There are many technical challenges needs to be addressed in Saudi Arabia such as enhancement and readiness of mobile services. Research [9] has argued that socioeconomic inequalities exist in Saudi Arabia with respect to the use of mobile government services, as more educated users are able to access to online services while less educated users could not utilize the online services.

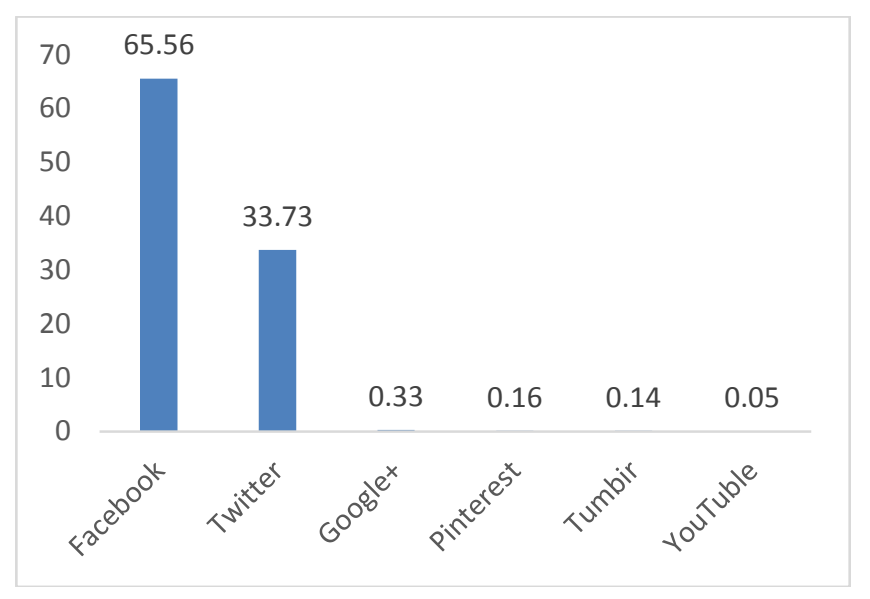

Fig. 2. Social Media access through Mobile (Jan 15 - Jan 16)

Respondents have chosen the Internet to complete diverse activities such as communication, education or being social [Fig 3]. It is important to address the elements that negatively influence the users to access the Internet such as lack of touching the product, customer service, security, trust, and negotiation [10]. The Saudi government has to address how to serve the needs of the educated users who access the Internet through mobile devices. This concern has been supported by the report from the World Bank (2012), that most Saudis are not able to avail the benefits of mobile government, as they are not aware of the complete usage of mobile devices. This challenge could be addressed through the awareness programs among the Saudis users about the benefits and usage of mobile commerce. The government may initiate steps to ensure the credibility of the system and provide assurance to the users that their data is safe and protected from adversaries. The government initiatives required a comprehensive legislative framework regarding cybercrimes, laws specifying the rights of citizens and responsibilities of data owner and data custodians.

The Saudi culture has a strong impact on users to shop traditionally such as touching the product to have a feel of it, visit the malls, spent time in the food court, negotiate the price and shop at the recommended businesses. These cultural events and values may indicate a lower rate of adoption of ecommerce by Saudi users compared to others culture. The cultural differences may also affect the rationale of Internet usage. The mindset of users from the specific cultures has been addressed by Hofstede [3] as "The collective programming of the mind which distinguishes the member of one human group from another. Culture, in this sense, includes a system of values. And values are among the building blocks of culture". He further defines the value of culture by stating that it's a central component of cultural and a broad tendency to prefer certain states of affairs over others. The future study will measure the value of Saudi culture and compare with others by addressing five dimensions developed by Hofstede. These dimensions namely Power Distance, Uncertainty Avoidance, Individualism-Collectivism, Masculinity-Femininity and Long 
versus Short-Term Orientation will reveal further factors influencing adoption of e-commerce in Saudi Arabia.

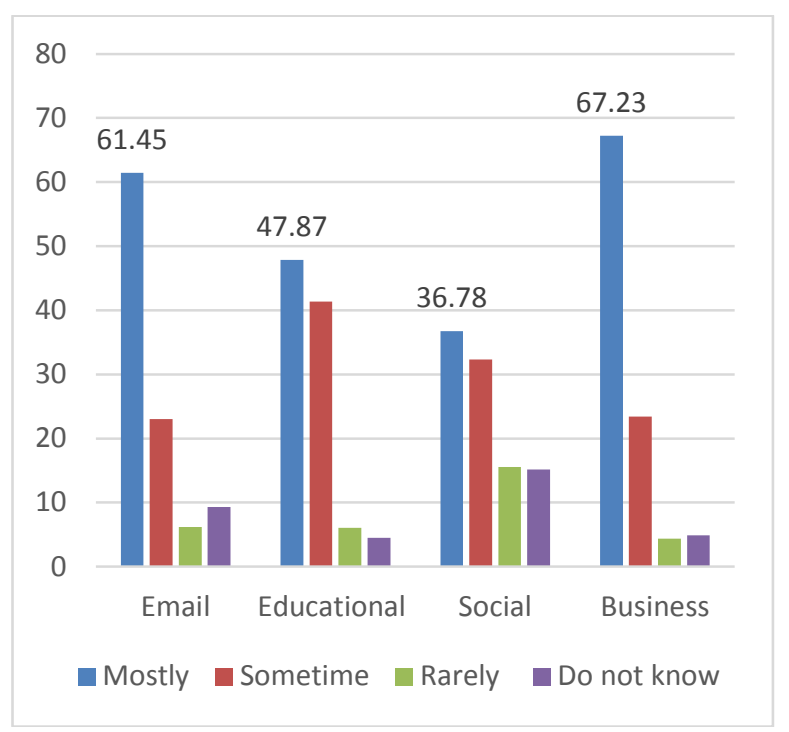

Fig. 3. Rationale for accessing the Internet

The issue which came to the fore was the lack of required IT infrastructure. Respondents have been noticed that the some of the barriers are not satisfied with the local service provider, such as Saudi Telecom \& Communication, Mobily, and Zain. The users prefer continuous availability and faster bandwidth and stronger security in place to protect their personal data. The respondents have a concern about the cost to access the Internet. They have suggested that the government should intervene to minimize the cost of accessing the Internet especially tariff on mobile access. This will benefit users who mostly access the Internet through mobile devices.

\section{CONCLUSION}

This study explored the factors that affected the Saudi citizens with respect to online shopping. The Internet usage from the perspective of cultural anthropology was studied, focusing on its influence on Saudi society. There is a high level of Internet penetration among the Saudi Arabian population. The results of this study show that the participants who were using Internet services are displeased with the services. There is a lack of certainty amongst the respondents about the current security measures in place to protect their data and privacy. Furthermore, some respondents who thought that the current charges to access the Internet are expensive. Differences have been reported on attitudes toward Internet searching and usage patterns among women and men. Women and men have little differences in their general attitudes toward the perception of the Internet. Patterns of gender difference show that the Saudi male users are likely to have positive attitudes towards the Internet. They spent more time on the Internet and used the Internet more extensively. With respect to technology usage in the Saudi Arab, traditionally men are considered as 'high tech' and expected to take a lead role in managing technology related tasks. The barriers that influenced the acceptance of e-commerce are privacy, security, the cost of accessing the Internet, social values and incapability of physically examining the products.

\section{ACKNOWLEDGMENT}

The author extends his appreciation to the Deanship of Scientific Research at King Saud University, represented by the Research Centre at the College of Business Administration, for funding this research.

\section{REFERENCES}

[1] U.S. Census Bureau News. Quarterly Retail E-Commerce Sales 4th Quarter 2015. Available at: https://www.census.gov/retail/mrts/www/data/pdf/ec_current.pdf (Accessed: 2 March 2016).

[2] PFS web. eCommerce Summary. Available at: http://www.pfsweb.com/pdf/global-ecommerce-book/2016-GlobaleCommerce-Book-USA.pdf (Accessed: 5 March 2016).

[3] Hofstede, G.H. (1984). Culture's consequences, International Differences in Work-Related Values. Beverly Hills, CA: Sage Publications.

[4] Adel. A. Alyoubi, "E-commerce in Developing Countries and how to Develop them during the Introduction of Modern Systems" International Conference on Communications, management, and Information technology, Volume 65, 2015, Pages 479-483

[5] Hussain, Atiya. "E-Commerce and Beyond: Opportunities for developing country SMEs.” International Trade Forum, no. 4. 2013.

[6] F. Meskaran and Z. Ismail, "Customers' trust in e-commerce: In collective culture setting," Information Retrieval \& Knowledge Management, 2012 International Conference on, Kuala Lumpur, 2012, pp. 182-186.

[7] M. Al-Hamar, R. Dawson, and L. Guan, "A Culture of Trust Threatens Security and Privacy in Qatar," Computer and Information Technology, 2010 IEEE 10th International Conference on, Bradford, 2010, pp. 991995.

[8] Moteb Ayesh Albugami, "E-Commerce and Economy: A Case Study of Saudi Arabia", International Journal of Information Technology, December 2015; Vol. 7 No. 2; ISSN 0973 - 5658916

[9] A.Alssbaiheen \& S. Love, "Exploring the Challenges of m-Government Adoption in Saudi Arabia" Electronic Journal of e-Government Volume 13 Issue 12015.

[10] Fahim Akhter, "Implement Fuzzy Logic to Optimize Electronic Business Success" International Journal of Advanced Research in Artificial Intelligence, 5(3), 2016 